Author has nothing to disclose with regard to commercial support.

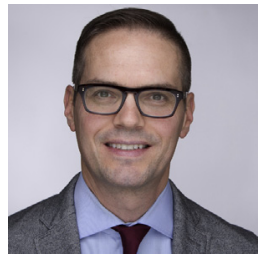

\section{UNDERSTANDING THE EFFICACY OF APNEIC OXYGEN \\ INSUFFLATION DURING THORACOSCOPIC LOBECTOMY}

To the Editor:

The recently published randomized controlled trial by Jung and colleagues ${ }^{1}$ outlining the use of apneic oxygen insufflation (AOI) through the nondependent (operative side) lumen of a double-lumen endotracheal tube (DL-ETT) showed that the incidence of hypoxemia during one-lung ventilation (OLV) was effectively reduced to $0 \%$ in the AOI group compared with $18 \%$ in the non-AOI controls $(P=.009)$. In addition, the decrease in the partial pressure of oxygen from 15 minutes to 45 minutes of OLV was also substantially reduced in the AOI group $(-29 \mathrm{~mm} \mathrm{Hg}$ vs $-69 \mathrm{~mm} \mathrm{Hg}$, respectively; $P=.005)$. Although one cannot dispute these differences in the incidence of hypoxemia and adequacy of oxygenation between their AOI and non-AOI groups, part of this difference may have been a function of how the DL-ETT of the nondependent lung was managed during the OLV itself. For example, Bussieres and colleagues ${ }^{2}$ recently suggested that by closing the operative side lumen to the ambient atmosphere during OLV - paradoxically, because it is usually opened with the belief that this will aid the egress of air-can actually have a beneficial effect itself. This is as a result of the nondependent lung continuing to absorb oxygen at the alveolar level, which subsequently decreases the airway pressure, and essentially draws in room air gas (containing poorly absorbed nitrogen) through this usually open lumen, which can subsequently contribute to the development of hypoxemia. In the study by Jung and colleagues, ${ }^{1}$ by simply insufflating oxygen into the same operative side lumen, they essentially may have prevented the drawing in of this room air, thus preventing this cause of hypoxemia. Indeed, had Jung and colleagues ${ }^{1}$ simply closed this lumen and not administered any oxygen, this alone may have prevented the development of the hypoxemia.

Whereas it may be difficult to completely disregard the benefits of AOI, perhaps a more suitable comparator would

\footnotetext{
The Editor welcomes submissions for possible publication in the Letters to the Editor section that consist of commentary on an article published in the Journal or other relevant issues. Authors should: • Include no more than 500 words of text, three authors, and five references. $\bullet$ Type with double-spacing. $\bullet$ See http://jtcs.ctsnetjournals.org/ misc/ifora.shtml for detailed submission instructions. • Submit the letter electronically via jtcvs.editorialmanager.com. Letters commenting on an article published in the JTCVS will be considered if they are received within 6 weeks of the time the article was published. Authors of the article being commented on will be given an opportunity of offer a timely response ( 2 weeks) to the letter. Authors of letters will be notified that the letter has been received. Unpublished letters cannot be returned.
}

have been a third group in which no gas was insufflated, but with the lumen closed to atmosphere, thus avoiding nitrogen getting into the lung. Without this, one may be erroneously left with the impression of an AOI benefit that is probably greater than it actually is, in part because of the management of the non-AOI group.

\section{Hilary P. Grocott, MD, FRCPC Department of Anesthesia University of Manitoba Winnipeg, Manitoba, Canada}

\section{References}

1. Jung DM, Ahn HJ, Jung SH, Yang M, Kim JA, Shin SM, et al. Apneic oxygen insufflation decreases the incidence of hypoxemia during one-lung ventilation in open and thoracoscopic pulmonary lobectomy: a randomized controlled trial. J Thorac Cardiovasc Surg. 2017;154:360-6.

2. Bussieres JS, Somma J, Del Castillo JL, Lemieux J, Conti M, Ugalde PA, et al. Bronchial blocker versus left double-lumen endotracheal tube in video-assisted thoracoscopic surgery: a randomized-controlled trial examining time and quality of lung deflation. Can J Anaesth. 2016;63:818-27.

http://dx.doi.org/10.1016/j.jtcvs.2017.07.022

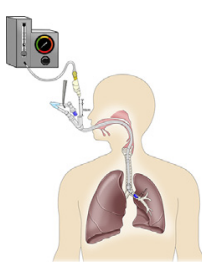

\section{BLOCKING THE DOUBLE-LUMEN ORIFICE VERSUS APNEIC OXYGENATION DURING 1-LUNG VENTILATION \\ Reply to the Editor:}

We greatly appreciate Grocott's interest and comment on our article.

In our study, apneic oxygen insufflation (AOI) decreased the incidence of hypoxemia and maintained partial pressure of oxygen $\left(\mathrm{PaO}_{2}\right)$ higher compared with the control group during 1- lung ventilation (OLV). The mechanism of AOI was suggested as aventilatory mass flow, which enables the oxygen absorbed in alveoli to be replaced by passive oxygen movement through an AOI catheter.

Grocott suggested another mechanism: partial blocking of the nondependent side of the double-lumen tube (DLT) by an oxygen insufflation catheter may have contributed to the higher $\mathrm{PaO}_{2}$ in the AOI group. He referenced an article by Bussieres and colleagues. ${ }^{2}$ That article compared the speed of lung collapse between the bronchial blocker (BB) and the DLT during OLV and reported slower lung collapse in the DLT. The suggested mechanism was continuous inflow of ambient air through the opening of the nondependent side of the DLT (aventilatory mass flow). They used the BB, the opening of which was closed when used. However, they did not report on hypoxia or $\mathrm{PaO}_{2}$ between the $\mathrm{BB}$ and the DLT.

The suggestion by Grocott that "just closing the lumen of the nondependent side of DLT would bring higher oxygenation by preventing aventilatory inward flow of room air and nitrogen trapping in the alveoli" is very interesting and worth studying. Our only concern is that blocking the 
Authors have nothing to disclose with regard to commercial support.

opening of the DLT without employing pre-OLV apnea (lung collapse) would significantly impair the surgical field. Bussieres and colleagues ${ }^{2}$ used the BB after applying pre-OLV apnea. Blocking the opening of the DLT during the lung inflation state will slow lung collapse and be beneficial in terms of $\mathrm{PaO}_{2}$ without doubt. Blocking the opening of the DLT after employing pre-OLV apnea is not known yet for its effect on $\mathrm{PaO}_{2}$ and therefore needs to be compared with the contemporary method of leaving it open or our AOI technique for better oxygenation in future studies.

Dae Myung Jung, $M D^{a}$ Hyun Joo Ahn, $M D, P h D^{a}$ Sin-Ho Jung, $P h D^{b}$ Mikyung Yang, $M D, P h D^{a}$ Jie Ae Kim, $M D, P h D^{a}$ Su Min Shin, $M D^{c}$ Suyong Jeon, $M D^{a}$ Departments of ${ }^{a}$ Anesthesiology and Pain Medicine and ${ }^{c}$ Thoracic and Cardiovascular Surgery Samsung Medical Centre Sungkyunkwan University School of Medicine ${ }^{b}$ Biostatistics and Clinical Epidemiology Centre Research Institute for Future Medicine Samsung Medical Centre Seoul, Korea

\section{References}

1. Bartlett RG Jr, Brubach HF, Specht H. Demonstration of aventilatory mass flow during ventilation and apnea in man. J Appl Physiol. 1959;14:97-101.

2. Bussieres JS, Somma J, Del Castillo JL, Lemieux J, Conti M, Ugalde PA, et al. Bronchial blocker versus left double-lumen endotracheal tube in video-assisted thoracoscopic surgery: a randomized-controlled trial examining time and quality of lung deflation. Can J Anaesth. 2016;63:818-27.

http://dx.doi.org/10.1016/j.jtcvs.2017.07.072

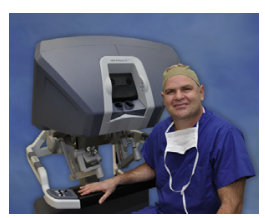

\section{THE MERIT OF OXYGEN INSUFFLATION DURING ONE-LUNG VENTILATION Reply to the Editor:}

Thoracic surgeons are often faced with patients who have hypoxemia during one-lung ventilation. An elegantly conducted randomized trial by Jung and colleagues ${ }^{1}$ recently published in the Journal suggests that in patients with preserved lung function, low-flow insufflation of oxygen to the operative side during one-lung ventilation prevents hypoxemia. In this issue of the Journal, Grocott's letter to the Editor ${ }^{2}$ comments on Jung and colleagues' trial ${ }^{1}$ and suggests that by maintaining the lumen of the operative
Author has nothing to disclose with regard to commercial support.

side closed, the continued absorption of oxygen from the down lung would decrease the instances of hypoxemia during one-lung ventilation. Grocott ${ }^{2}$ cites a randomized trial by Bussières and colleagues ${ }^{3}$ as a basis for his hypothesis. Grocott ${ }^{2}$ also argues that a group in which the operative side of the double-lumen tube was closed to room air should have been included in the trial of Jung and colleagues. ${ }^{1}$

This is an intriguing proposition, but it is unfortunately not supported by published data. Bussières and colleagues ${ }^{3}$ conducted a randomized trial comparing one-lung ventilation with a double-lumen tube or a bronchial blocker. The end point of the study was time to complete lung collapse during video-assisted lung resection. The trial showed that time to complete lung collapse was significantly shorter when a bronchial blocker was used for one-lung ventilation than when a double-lumen tube used. Bussières and colleagues ${ }^{3}$ did not address oxygen levels, nor did they provide any data on oxygen saturation during one-lung ventilation. In fact, 1 of their patients in the bronchial blocker group was excluded from analysis because of the inability to achieve proper oxygen saturation after initiation of one-lung ventilation. I respectfully disagree with Grocott. $^{2}$ The randomized trial by Jung and colleagues ${ }^{1}$ was conducted in accordance with the best available evidence on one-lung ventilation. A third group would have obscured their findings and clouded their message. The big question regarding the trial of Jung and colleagues ${ }^{1}$ is whether these findings will hold in patients with compromised lung function. ${ }^{4}$ Although the findings of Bussières and colleagues ${ }^{3}$ are important for teams involved in thoracoscopic lung resection, these concerns are not relevant to the trial of Jung and colleagues. ${ }^{1}$

Benny Weksler, MD

Division of Thoracic Surgery University of Tennessee Health Science Center Memphis, Tenn

\section{References}

1. Jung DM, Ahn HJ, Jung SH, Yang M, Kim JA, Shin SM, et al. Apneic oxygen insufflation decreases the incidence of hypoxemia during one-lung ventilation in open and thoracoscopic pulmonary lobectomy: a randomized controlled trial. J Thorac Cardiovasc Surg. 2017;154:360-6.

2. Grocott HP. Understanding the efficacy of apneic oxygen insufflation during thoracoscopic lobectomy. J Thorac Cardiovasc Surg. 2017;154:2122.

3. Bussières JS, Somma J, Del Castillo JL, Lemieux J, Conti M, Ugalde PA, et al. Bronchial blocker versus left double-lumen endotracheal tube in video-assisted thoracoscopic surgery: a randomized-controlled trial examining time and quality of lung deflation. Can J Anaesth. 2016;63:818-27.

4. Weksler B. During one-lung ventilation, K.I.S.S.-keep it simple surgeons J Thorac Cardiovasc Surg. 2017;154:367-8.

http://dx.doi.org/10.1016/j.jtcvs.2017.07.071 